\title{
ESTRATÉGIA COMO PROCESSO DE APRENDIZAGEM: UM ESTUDO EMPÍRICO DE SEUS FATORES DETERMINANTES EM UMA EMPRESA DE TI
}

\author{
STRATEGY AS A LEARNING PROCESS: AN EMPIRICAL STUDY OF ITS \\ DETERMINANTS IN A COMPANY OF IT
}

\section{ESTRATEGIA COMO UN PROCESO DE APRENDIZAJE: UN ESTUDIO EMPÍRICO DE SUS DETERMINANTES EN UNA EMPRESA DE TI}

\section{José Geraldo Pereira Barbosa}

Doutor em Administração pela Universidade Federal do Rio de Janeiro - UFRJ

Coordenador e professor do Mestrado em Administração e Desenvolvimento Empresarial da Universidade Estácio de Sá - MADE/UNESA

E-mail: jose.geraldo@estacio.br (Brasil)

\section{Nelson Lopes Marques Filho}

Mestre em Administração Empresarial pela Faculdade Estácio de Sá

E-mail: nmarques@yahoo.com.br (Brasil)

\section{Jorge Augusto de Sá Brito e Freitas}

Doutor em Administração de Empresas pela Pontifícia Universidade Católica do Rio de Janeiro PUC/RJ

Professor da Universidade Estácio de Sá - UNESA

E-mail jorge.freitas@estacio.br (Brasil)

\section{Silvestre Prado de Souza Neto}

Doutor em Administração pela Universidade de São Paulo - USP

Professor da Fundação Centro de Ciências e Educação Superior à Distância do Estado do Rio de Janeiro

E-mail: silvestrenet0@uol.com.br (Brasil) 


\title{
ESTRATÉGIA COMO PROCESSO DE APRENDIZAGEM: UM ESTUDO EMPÍRICO DE SEUS FATORES DETERMINANTES EM UMA EMPRESA DE TI
}

\section{RESUMO}

O objetivo dessa pesquisa foi verificar em uma empresa brasileira fabricante de computadores, se o seu processo de formulação de estratégias empresariais é entendido, basicamente, como um processo de aprendizagem. Entrevistas baseadas em roteiro de perguntas, observação direta, pesquisa documental e análise de conteúdo foram os instrumentos utilizados em uma pesquisa de campo com abordagem qualitativa. A primeira etapa da pesquisa consistiu na identificação de sete ações estratégicas recentemente implantadas na empresa. A etapa subseqüente procurou verificar, a partir da análise do processo de escolha das ações estratégicas identificadas na primeira etapa, a intensidade da presença na empresa de nove características que, no entendimento de autores citados no referencial teórico, são comuns às empresas que entendem a formulação de estratégias como um processo de aprendizagem. Os resultados da pesquisa sugerem que quatro características - intraempreendedorismo, força da gerência intermediária, estrutura flexível e ambiente externo instável estão fortemente presentes na empresa; duas características - pequena ênfase em planejamento e controle; e emergência de estratégias não planejadas - podem ser enquadradas como grau médio de presença; e três características - ênfase em estratégia como guarda-chuva; ênfase em aprendizagem de laço duplo; e ênfase em estratégia como perspectiva - se mostraram pouco presentes. A pesquisa permitiu constatar que as ações estratégicas mais eficazes da empresa pesquisada não se desenvolveram mediante processos claros, bem ordenados, controlados e explícitos, mas foram moldadas, de forma relevante, por um processo de aprendizagem centrado na trajetória passada da empresa.

Palavras-chave: Estratégia; Processo de Aprendizagem; Empreendedorismo; Tecnologia da Informação.

\section{STRATEGY AS A LEARNING PROCESS: AN EMPIRICAL STUDY OF ITS DETERMINANTS IN A COMPANY OF IT}

\begin{abstract}
The aim of this study was to verify in a Brazilian manufacturer of computers, if its process of formulating business strategies is understood primarily as a learning process. Interviews based on a script of questions, direct observation, archival research and content analysis were the instruments used in a field research with a qualitative approach. The first stage of the research was the identification of strategic actions recently implemented in the company. The subsequent stage verified from the analysis of the process of choosing seven strategic actions identified in the first stage, the intensity of the presence in the company of nine characteristics that, according the authors cited in the theoretical framework, are common to companies who understand the formulation strategies as a learning process. The survey results suggest that four features - intrapreneurship, strength of middle management, flexible organizational structure and unstable external environment - are strongly present in the company; two features - little emphasis on planning and control, and emergency of unplanned strategies - can be classified as average degree of presence, and three characteristics - emphasis on strategy as umbrella; emphasis on double-loop learning, and emphasis on strategy as perspective - proved to be present in low level. The research revealed that the most effective strategic actions of the company surveyed were not developed through clear, well ordered, controlled and explicit processes, but were shaped, in a relevant way, for a learning process focused on the past history of the company.
\end{abstract}

Keywords: Strategy; Learning Process; Entrepreneurship; Information Technology; Strategic Action. 
José Geraldo Pereira Barbosa, Nelson Lopes Marques Filho, Jorge Augusto de Sá Brito e Freitas \& Silvestre Prado de Souza Neto

\section{ESTRATEGIA COMO UN PROCESO DE APRENDIZAJE: UN ESTUDIO EMPÍRICO DE SUS DETERMINANTES EN UNA EMPRESA DE TI}

\section{RESUMEN}

El objetivo de este estudio fue verificar en un fabricante brasileño de computadoras, el proceso de formulación de estrategias de negocios se entiende principalmente como un proceso de aprendizaje. Entrevistas basado entrevista estructurada, la observación, la investigación documental y análisis de contenido fueron los instrumentos utilizados en un estudio de campo con un enfoque cualitativo. La primera etapa de la investigación implicó la identificación de siete acciones estratégicas recientemente implementadas en la empresa. El siguiente paso fue comprobar, a partir del análisis del proceso de selección de las acciones estratégicas identificadas en la primera fase, la intensidad de la presencia en la compañía de nueve características que, en el entendimiento de los autores citados en el marco teórico, son comunes a las empresas que entienden la formulación estrategias como un proceso de aprendizaje. Los resultados del estudio sugieren que las cuatro características intrapreneurship, la fuerza de los mandos intermedios, flexible y el medio ambiente externo inestable - están muy presentes en la empresa, dos características - La cursiva es pequeño en la planificación y el control, y estrategias de emergencia imprevistas - puede ser clasificados como grado medio de presencia, y cuenta con tres - un énfasis en la estrategia como un paraguas, el énfasis en el aprendizaje de bucle doble, y un énfasis en la estrategia como perspectiva - resultó pequeños regalos. La investigación permitió establecer que las acciones estratégicas más eficaces para la empresa investigada a través de procesos no desarrollados clara y bien ordenada, controlada y explícita, sino que se enmarca tan relevante para un proceso de aprendizaje centrado en el historial de la empresa.

Palabras-clave: Estrategia; Proceso de Aprendizaje, El Espíritu Empresarial; Tecnología de la Información. 


\section{INTRODUÇÃO}

Para Weick e Roberts (1993), a aprendizagem organizacional consiste de ações interrelacionadas de indivíduos, ou seja, de uma 'inter-relação ponderada' que resulta numa mente coletiva. Eles afirmam que as ideias estão fundadas em ações individuais que, ao serem integradas, passam a ser entendidas "como caminhos pelos quais atividades distintas e inter-relacionadas de experiências (ou padrões) de alta hierarquia emergem” (WEICK e ROBERTS, 1993, p. 374).

Por sua vez, Nelson e Winter (1982) afirmam que as organizações não são totalmente governadas pela racionalidade e que não existe um vetor único que norteie a mudança. As mudanças ocorreriam por meio de interações cumulativas entre sistemas, a que denominaram rotinas. Elas seriam, então, padrões repetitivos de atividade que sustentam e controlam o funcionamento da organização.

Reunindo as argumentações acima, Mintzberg, Ahlstrand e Lampel (2000) sugerem então que a natureza complexa e imprevisível do ambiente organizacional, em conjunção com a amplitude do conhecimento necessário à criação de estratégias, impede uma utilização eficaz de mecanismos de planejamento de estratégias. Para esses autores, a estratégia deve resultar de um processo de aprendizagem contínuo, no qual formulação e implementação tornam-se indistinguíveis.

A revisão da literatura que trata da formação de estratégia empresarial como um processo de aprendizagem, objeto da seção 2 deste artigo, indicou que as empresas onde tal entendimento prevalece são caracterizadas por determinadas características que podem estar presentes em menor ou maior grau. Desta forma, este estudo pretende, com o auxílio de uma pesquisa de campo em uma empresa do setor de tecnologia da informação (TI), identificar a presença destas características e responder à seguinte questão:

O processo de formulação de estratégias empresariais da empresa pesquisada é entendido como um processo de aprendizagem? Ou seja, em que grau as características relacionadas ao fenômeno da aprendizagem estratégica estariam presentes na empresa pesquisada? 


\section{REFERENCIAL TEÓRICO: A FORMAÇÃO DA ESTRATÉGIA EMPRESARIAL COMO UM PROCESSO DE APRENDIZAGEM}

\subsection{EMERGÊNCIA DE ESTRATÉGIAS NÃO PLANEJADAS}

Os pesquisadores pioneiros de pesquisas em estratégia (ANDREWS, 2006; ANSOFF, 1987, 1991, 1993) usaram os conceitos de formulação e implantação para descreverem o processo de elaboração de estratégias empresariais. Na formulação de estratégia, o passo inicial é do Chief Executive Officer (CEO) formulando o novo plano estratégico, apoiado pelo seu grupo de assessoramento, e, em alguns casos, por alguns consultores externos com experiência em negócios e economia. Subsequentemente o plano estratégico é implantado, algumas vezes, com o apoio de mudança organizacional.

Entretanto, frequentemente os planos estratégicos desaparecem celeremente nas gavetas, tendo apenas um impacto limitado nas operações reais da organização e, assim, permanecem como 'tigres de papel'. O planejamento estratégico é comparado então a "um ritual da dança: não tem nenhum efeito no clima posterior, mas faz aquele que se engajou na dança se sentir que está no controle" (ACKOFF, 1979, p. 359).

Desde longo tempo, tem sido suposto por diversos autores, pesquisadores e executivos que a formulação da estratégia assume capacidade de previsão ambiental; o desdobrar do processo de formação estratégica na programação; e a habilidade de impor as estratégias resultantes (MINTZBERG, 1994). As intenções estratégicas se desdobram em processos e procedimentos que resultam num conjunto de diretrizes deliberadas e que, conscientemente, influenciarão o rumo das decisões no futuro da organização (MINTZBERG, 1978, 1994).

Contrariamente a essa argumentação, várias pesquisas mostram que nem toda organização apresenta estratégias intencionais, mas nem por isso se pode afirmar não terem elas processos de formulação de estratégias (MINTZBERG, AHLSTRAND e LAMPEL, 2000).

Para alguns autores há uma clara distinção entre os termos formulação e formação de estratégia. A formação ou construção da estratégia é vista como um processo contínuo de desenvolvimento de estratégias organizacionais, enquanto a formulação estratégica se caracteriza como um processo intencionalmente construído, em que as decisões são feitas, tanto por pessoas como pelos grupos intraorganizacionais (PETTIGREW, 1977).

Para Mintzberg, Ahlstrand e Lampel (2000), toda estratégia situa-se numa posição entre deliberada e emergente. Nenhuma se situa puramente em uma das duas pontas. Hill e Jones (2004)

Revista Ibero-Americana de Estratégia - RIAE, São Paulo, v. 11, n. 3, p. 05-32, set./dez. 2012. 
reconhecem a importância tanto de estratégias intencionais (deliberadas) quanto de emergentes e salientam que a gerência necessita reconhecer o processo de emergência e intervir quando apropriado. Estratégias não intencionais emergem, trilhando outros caminhos além dos processos formais, e a gerência necessita avaliá-las e selecionar aquelas que se alinhem com a visão da organização.

\subsection{PEQUENA ÊNFASE EM PLANEJAMENTO E CONTROLE}

A ênfase exagerada no planejamento estratégico como abordagem ao processo de formulação e implantação de estratégias tem sido criticada, notadamente por Mintzberg (1994). Criticando a excessiva formalização do planejamento estratégico, ele afirma que:

[...] formalização implica uma sequência racional, que perpassa todos os procedimentos administrativos, até uma ação final. Mas, a implantação da estratégia como um processo de aprendizagem pode seguir numa direção oposta, de igual forma (MINTZBERG, 1994, p.111).

Nesta mesma direção, Collier, Fishwick e Floyd (2004) afirmam que o planejamento em si é menos importante que os efeitos de aprendizagem causados pelo próprio processo de planejamento.

Mintzberg (1994) tem argumentado que muito da estratégia convencional está baseada no planejamento das intenções explícitas, ignorando os efeitos da implantação, ou seja, reduzindo a possibilidade de emergência de estratégias. O conceito de estratégia emergente está mais interessado em procurar explicar o modo pelo qual essas intenções explícitas são adaptadas para fornecer novos entendimentos num ambiente dinâmico. Tal conceituação de estratégia, ou o processo de formulação da mesma, enfatiza a aprendizagem estratégica e cria espaço para que a organização se habilite a experimentar.

$\mathrm{O}$ autor acima argumenta ainda que a estratégia deliberada está associada com o controle gerencial e é auxiliada pela garantia de que intenções estratégicas gerenciais sejam postas em ação, enquanto que a estratégia emergente enfatiza o entendimento dos objetivos organizacionais a partir dos resultados das ações. Para o autor:

Quando as empresas entenderem a diferença entre planejamento e pensamento estratégico, elas poderão retornar ao que o processo de se fazer estratégia deveria ser: capturar o que os gerentes aprendem de todas as fontes (tanto as visões internas do seu pessoal ou das suas experiências advindas de outrem através da organização e os dados obtidos do mercado externo e similares), e então sintetizar o que aprendeu transformando em visão na direção do lucro desejado para o negócio (MINTZBERG, 1994, p. 107). 
José Geraldo Pereira Barbosa, Nelson Lopes Marques Filho, Jorge Augusto de Sá Brito e Freitas \& Silvestre Prado de Souza Neto

Nas pesquisas de Mintzberg e seus colaboradores na Universidade McGill foram registradas ações em empresas pesquisadas que um observador externo perceberia como estratégicas e que, de quando em vez, se formavam sem a presença clara de um plano. Assim, a estratégia começou a ser pensada não em termos de intenções deliberadas, mas em termos de ações que surgem (emergem) sem um planejamento detalhado. Não demorou muito para que os conceitos de estratégia e aprendizagem organizacional se relacionassem. O conceito de estratégia emergente abre as portas para a aprendizagem ao reconhecer a importância da experimentação. Uma (ou mais de uma) ação estratégica é adotada, o feedback é recebido e o processo continua até que toda a organização a(s) adote como estratégica (s) (MINTZBERG, 1994).

\subsection{GRANDE ÊNFASE EM ESTRATÉGIA COMO PERSPECTIVA}

Para Nelson e Winter (1982), os reservatórios de memória organizacional - regras e rotinas são códigos de inferências escritos pela experiência organizacional. Como padrões de atividades, eles são também fontes de competência e de vantagem competitiva. Regras e rotinas atuais e vigentes refletem a aprendizagem passada e sugerem que podem ser bem mais que meios de transporte do antigo conhecimento - elas podem produzir estabilidade e, ainda mais, render, através da transformação da organização e de seus membros, em termos de evolução, propiciando experimentação continuada para resolução de problemas inesperados ou imprevistos. Para esses autores, regras são explícitas, enquanto rotinas são tácitas. As regras são escritas e reforçáveis, enquanto as rotinas são implícitas, inferidas da prática, e relembradas pelo 'fazer'.

Nonaka (1994) tem sugerido que o conhecimento organizacional é criado através de um diálogo contínuo entre o que se sabe explicitamente (como regra) e o que se entende tacitamente (como rotina). Conhecimento explícito agrega entendimentos que estão disponibilizados na forma concreta e comunicável (NONAKA e TAKEUCHI, 1997; POLANYI, 1962). Esse conhecimento pode ser expresso em palavras, números, diagramas, figuras, fórmulas e esquemas. Eles podem ser mais facilmente compartilhados do que o conhecimento tácito. Como insights subjetivos ou emoções, o conhecimento tácito fica incrustado nas rotinas do dia-a-dia e existe de forma não articulada, pessoal e difícil de verbalizar ou comunicar (NONAKA e TAKEUCHI, 1997). Quando uma nova regra é introduzida, os membros da organização devem, primeiramente, encontrar um ajuste entre a regra que está sendo introduzida e as antigas regras e rotinas (MEYER e GOES, 1988). As regras e rotinas antigas representam o conhecimento antigo que tem sido usado visando alcançar as prioridades e necessidade de até então.

Revista Ibero-Americana de Estratégia - RIAE, São Paulo, v. 11, n. 3, p. 05-32, set./dez. 2012. 
Ao longo do tempo, aprendendo com a experiência, os membros da organização tentarão se acomodar aos novos requerimentos, requisitos e exigências da nova regra (DIERICKX e COOL, 1989). Todos tentarão desenvolver novos meios para operar dentro dos limites e do confinamento propostos pela nova regra, aprendendo a utilizá-la para reconhecer problemas e como se organizar em coalizões para apoiar mudanças, quando elas forem imperativas.

Levitt e March (1988) caracterizam a memória como a forma tácita do saber. Walsh (1991, p. 58) é mais pragmático ao afirmar que "memória é a faculdade de reter e rever coisas passadas". Acrescenta ainda que uma "organização é uma rede de significados compartilhados intersubjetivamente, que é sustentada através do desenvolvimento e uso de uma linguagem comum e de interações sociais diárias" (WALSH, 1991, p. 60).

A memória organizacional pode ser abstrata ou concreta. Ela compreende conceitos não estruturados e informações que estão presentes na cultura organizacional e nas mentes dos seus membros, e pode ser parcialmente representada pela ajuda da memória concreta (física) armazenada pelos bancos de dados. A memória organizacional compreende também os conceitos estruturados e informação que podem ser representados por arquivos e registros computadorizados (WALSH e UNGSON, 1991; WALSH, 1995)

Para Pettigrew (1977), a estratégia seria reconhecida em:

[...] escolhas (que) são feitas e colocadas em ação em processos que envolvem indivíduos e seus grupos, em diferentes níveis organizacionais, (e) que se desenvolvem na formação de um padrão de pensamentos sobre o mundo, de avaliação e de atitudes sobre o mesmo. (PETTIGREW, 1977, p. 78).

Nessa perspectiva, a estratégia seria originada a partir do contexto, entendendo-se o contexto como o conjunto de variáveis formado pelos atributos da organização: tempo, cultura, ambiente interno (e seu nível de estabilidade, ou mutabilidade), atividades internas, estrutura, aparato tecnológico, sua(s) liderança(s) e sistema político interno. Todos esses elementos influenciam o processo de escolhas, opções e ações decisórias colocadas à disposição da organização (PETTIGREW, 1977). Para esse autor, os próprios resultados de ações estratégicas influenciam a formulação de estratégias, uma vez que eles passam a fazer parte do 'novo' contexto, compondo novas variáveis do processo de decisão. Esse novo contexto pode prover condições que justifiquem a formulação de novas opções ou ações estratégicas ou, em função de as condições organizacionais ou ambientais não terem sofrido alterações maiores, manter as estratégias em vigor.

Revista Ibero-Americana de Estratégia - RIAE, São Paulo, v. 11, n. 3, p. 05-32, set./dez. 2012. 
José Geraldo Pereira Barbosa, Nelson Lopes Marques Filho, Jorge Augusto de Sá Brito e Freitas \& Silvestre Prado de Souza Neto

\subsection{GRANDE ÊNFASE EM APRENDIZAGEM DE LAÇO DUPLO}

Enquanto a estratégia deliberada focaliza o controle (certificando-se de que as intenções estratégicas são colocadas em ação), a estratégia não planejada emerge a partir da aprendizagem adquirida na execução de ações intencionais e de adaptações necessárias. Portanto, a aprendizagem estratégica ocorreria na interface entre pensamento e ação, quando os atores refletem sobre os resultados de suas ações. (MINTZBERG, AHLSTRAND e LAMPEL, 2000). Ações isoladas são desenvolvidas, feedbacks positivos são recebidos, e o processo prossegue até que a organização venha a convergir para um padrão, um modo de agir, que passe a ser a estratégia. Nessa mesma direção também aponta Weick (1979) ao afirmar que a inteligibilidade (sensemaking) se origina na reflexão e no exame do passado.

Nessa mesma direção, Argyris (1977) enfatiza a importância de uma abordagem mais ampla ao processo de detecção e correção de erros. Quando a organização faz mais do que monitorar desvios, o processo é denominado de aprendizagem de laço duplo. A aprendizagem de laço simples surge de respostas a questões como: ‘quais são os requisitos mínimos?' ou 'quais são as vantagens e desvantagens de determinada decisão?'. A aprendizagem de laço duplo questiona como foram criados os requisitos ou o porquê das decisões tomadas. A teoria do laço duplo envolve aprendizagem visando mudança em valores e suposições subjacentes. Na aprendizagem de laço duplo, suposições subjacentes a visões presentes na organização são questionadas e hipóteses sobre os comportamentos são publicamente testadas. O resultado final dessa aprendizagem deve ser o crescimento da efetividade nas tomadas de decisão e melhor aceitação das falhas e dos erros.

Para Crossan, Lane e White (1999), a aprendizagem organizacional (AO) é um processo em que novas ideias e ações fluem de indivíduos para os níveis grupal e organizacional. No caminho oposto, o que já se aprendeu retorna da organização para o grupo e para o indivíduo, afetando como as pessoas pensam e agem. Esse fluxo de ida e de volta cria uma tensão entre a assimilação do novo aprendizado (feedforward) e o aproveitamento ou uso do que já se aprendeu (feedback).

No feedforward, o conhecimento adquirido pelos indivíduos (e que se encontra em seus mapas mentais individuais) segue o caminho do grupo ou dos times e da própria organização sendo 'encerebrado' (embrained), incorporado e aculturado (BLACKLER, 1995), na forma de rotinas ou procedimentos ou normas ou formas de trabalhar específicas e únicas da organização. Já no feedback, o conhecimento circula igualmente entre os grupos ou direto da organização para o indivíduo, que recebe os mapas mentais compartilhados e os absorve, processa e codifica, modificando, assim, sua visão do mundo e seu comportamento no trabalho e na vida social.

Revista Ibero-Americana de Estratégia - RIAE, São Paulo, v. 11, n. 3, p. 05-32, set./dez. 2012. 
A aprendizagem estratégica seria, segundo Mintzberg, Ahlstrand e Lampel (2000), o resultado do processo de reflexão sobre o passado. É o processo de obtenção de inteligibilidade retrospectiva.

\title{
2.5 FORÇA DA GERÊNCIA MÉDIA
}

Entretanto, para que a aprendizagem seja efetiva e percorra toda a organização, um forte envolvimento da gerência média torna-se essencial. (COLLIER, FISHWICK e FLOYD, 2004) Nonaka e Takeuchi (1997, p. 16) afirmam que:

\begin{abstract}
Os gerentes de nível médio servem como elo entre os idéias visionários da alta gerência e a realidade quase sempre caótica dos funcionários da linha de frente da empresa. Os gerentes de nível médio são mediadores entre a mentalidade de "o que deveria ser" da alta gerência e a mentalidade "de o que é" dos funcionários de linha, criando negócios de nível médio e conceitos de produto.

Os gerentes de nível médio desempenham um papel-chave no processo de criação de conhecimento. Resumem o conhecimento tácito tanto dos funcionários da linha quanto dos executivos seniores, tornando explícito e incorporando-o a novos produtos e tecnologias.
\end{abstract}

\subsection{LIBERDADE PARA EMPREENDEDORISMO}

De acordo com Burgelman (1983), iniciativas estratégicas freqüentemente se desenvolvem no chão de fabrica, e são então impulsionadas por gerentes de nível médio que por sua vez buscam, por meio de um processo de competição interna, a autorização da direção. A direção da empresa pode influenciar as iniciativas por meio do contexto estrutural (arquitetura organizacional, sistemas de informação e de avaliação de desempenho, sistemas de recompensa e punição). O desenvolvimento das iniciativas estratégicas levaria ao refinamento ou mudança da estratégia vigente, e acabaria por determinar, após algum tempo, o contexto estratégico.

\subsection{ORGANIZAÇÃO IMERSA EM AMBIENTE INSTÁVEL}

Vários fatores podem tornar o ambiente dinâmico, incluindo regulamentação, mudanças imprevistas na economia, mudanças inesperadas na demanda do cliente ou na oferta do concorrente, aparecimento de inovações tecnológicas radicais, exigências dos clientes por criatividade ou por novidades freqüentes. Para Hitt, Ireland e Hoskisson (2003) tal ambiente é sinônimo de grande rivalidade entre os concorrentes, ou seja, as vantagens competitivas da empresa não são protegidas

Revista Ibero-Americana de Estratégia - RIAE, São Paulo, v. 11, n. 3, p. 05-32, set./dez. 2012. 
José Geraldo Pereira Barbosa, Nelson Lopes Marques Filho, Jorge Augusto de Sá Brito e Freitas \& Silvestre Prado de Souza Neto

de imitação e onde a imitação ocorre rapidamente e talvez sem necessidade de grandes dispêndios financeiros. Engenharia reversa e a alta taxa de difusão tecnológica nestes mercados facilitam a imitação. O mercado de computadores pessoais é um bom exemplo. Geralmente as empresas, nestes mercados, se apóiam fortemente em inovações para crescerem. Em vez de se concentrarem em proteger, manter e estender vantagens competitivas, como é o caso dos mercados de ciclo lento, as empresas se concentram em aprender como desenvolver, rapidamente e de forma contínua, novas vantagens competitivas que sejam superiores àquelas substituídas. É comum em certos setores econômicos as empresas usarem alianças estratégicas para ganharem acesso a novas tecnologias e então desenvolverem e introduzirem novos produtos no mercado.

Para Mintzberg, Ahlstrand e Lampel (2000), qualquer organização que atue em ambientes dinâmicos e imprevisíveis terá que aprender de modo a entender o que está acontecendo. Para os autores, isto também é válido para uma organização que se veja diante de enfrente uma situação realmente nova (empresas surpreendidas por descontinuidades tecnológicas, por exemplo).

\subsection{PREFERÊNCIA POR ESTRUTURA ORGANIZACIONAL FLEXÍVEL}

Os diferentes tipos de estrutura organizacional propiciam o aprendizado e a construção do conhecimento. As estruturas mecanicistas predispõem ao aprendizado de novos comportamentos embora delimitados aos já existentes na organização. Por outro lado, as estruturas orgânicas favorecem o aprendizado de novas capacidades e habilidades que diferem completamente dos então existentes. Fomentam a descoberta, a eficiência, e a flexibilidade (LIAO, FEI e LIU, 2008).

De acordo com Taylor e McAdam (2004) os sistemas orgânicos são os mais apropriados quando as condições do ambiente estão constantemente em mudança. Neste tipo de estrutura, a natureza, direção e qualidade de comunicação bem como a importância dada às pessoas como indivíduos, é relevante. Em contrapartida, os sistemas mecanicistas evidenciam uma estrutura hierárquica pautada na especialização. A comunicação tende a ser instrucional, sendo que a fidelidade e a obediência ao superior hierárquico são obrigatórias. Os trabalhadores, neste sistema, aderem a procedimentos e regras e têm os direitos e obrigações devidamente delimitados e definidos para o exercício de suas funções. Controle, autoridade e comunicação são mantidas pela hierarquia. Princípios similares foram disseminados pelos ensinamentos clássicos de Weber (1947) e Fayol (1949) (TAYLOR e McADAM, 2004).

Revista Ibero-Americana de Estratégia - RIAE, São Paulo, v. 11, n. 3, p. 05-32, set./dez. 2012. 


\subsection{GRANDE ÊNFASE EM ESTRATÉGIA COMO GUARDA-CHUVA}

De acordo com Mintzberg, Ahlstrand e Lampel (2000), o papel da liderança não é, então, o de preconceber estratégias deliberadas, mas de gerenciar o processo de aprendizagem estratégica, de modo a facilitar a emergência de ações estratégicas originais. Nessa mesma direção também aponta Quinn (1989) quando afirma que em organizações bem gerenciadas, os gerentes guiam de forma pró-ativa e incremental os cursos de ações e eventos (iniciativas estratégicas), na direção de uma estratégia pretendida que prevalecerá no período de mudanças.

Este referencial teórico termina com uma síntese do que os autores acima entendem como a formação de estratégia como um processo de aprendizado.

\footnotetext{
Se a estratégia emergente significa, literalmente, ordem não pretendida, então os padrões podem simplesmente se formar, movidos por forças externas ou necessidades internas, em vez de por pensamentos conscientes de qualquer dos agentes. O verdadeiro aprendizado tem lugar na interface de pensamento e ação, quando os agentes refletem sobre o que fizeram (MINTZBERG, AHLSTRAND e LAMPEL, 2000, p. 147).
}

Assim, as proposições dos autores visitados no referencial teórico possibilitaram aos autores da presente pesquisa identificar (e nomear) as características organizacionais e situacionais de empresas onde a formação da estratégia ocorre de forma determinante como um processo de aprendizado. Estas características, sublinhadas e marcadas em negrito ao longo dos parágrafos anteriores, são:

- Emergência de estratégias não planejadas;

- Pequena ênfase em planejamento e controle;

- Grande ênfase em estratégia como perspectiva;

- Grande ênfase em aprendizagem de laço duplo;

- Força da gerência média;

- Liberdade para intraempreendedorismo;

- Organização imersa em ambiente instável;

- Preferência por estrutura organizacional flexível; e

- Grande ênfase em estratégia como guarda-chuva.

Revista Ibero-Americana de Estratégia - RIAE, São Paulo, v. 11, n. 3, p. 05-32, set./dez. 2012. 
José Geraldo Pereira Barbosa, Nelson Lopes Marques Filho, Jorge Augusto de Sá Brito e Freitas \& Silvestre Prado de Souza Neto

\section{METODOLOGIA}

O presente estudo, uma pesquisa de campo com finalidade descritiva (VERGARA, 2005), foi desenvolvido na empresa BITWAY Computadores, cuja razão social é BITSHOP Indústria, Comércio e Importação Ltda. Trata-se de uma empresa de médio porte, pertencente ao setor de TI, estabelecida na cidade de Ilhéus, Estado da Bahia.

Foram realizadas entrevistas em profundidade com oito pessoas: os dois sócios proprietários, três gerentes (Industrial, Negócios e Normatização), e três sócios de uma empresa parceira, a Ata Serviços.

A pesquisa teve como ponto de partida a identificação na literatura de características organizacionais e situacionais de empresas que sugerem a ocorrência de formação de estratégias como um processo de aprendizagem. Estas características são:

- Emergência de estratégias não planejadas;

- Pequena ênfase em planejamento e controle;

- Grande ênfase em estratégia como perspectiva;

- Grande ênfase em aprendizagem de laço duplo;

- Força da gerência média;

- Liberdade para intraempreendedorismo;

- Organização imersa em ambiente instável;

- Preferência por estrutura organizacional flexível; e

- Grande ênfase em estratégia como guarda-chuva.

A escolha da empresa BITWAY, uma empresa de médio porte, deveu-se ao fato de a mesma estar estabelecida no setor de tecnologia da informação (TI), reconhecidamente um mercado de ciclo rápido, marcado pela forte presença de empreendedorismo, instabilidade ambiental e necessidade de estruturas organizacionais flexíveis (orgânicas) o que já indicaria, em princípio, a presença de 3 das características acima listadas.

A primeira etapa da pesquisa de campo consistiu na identificação das ações estratégicas recentemente implantadas. A segunda etapa procurou verificar a intensidade da presença na empresa das características acima listadas, e foi conduzida a partir da análise do processo de escolha das ações estratégicas identificadas na primeira etapa. As informações pertinentes a cada uma das 
etapas foram coletadas por meio de entrevistas e com utilização de um roteiro semiestruturado de perguntas. As entrevistas foram gravadas em áudio e vídeo, no próprio local de trabalho da cada participante, para posterior transcrição (GIL, 1994). Ainda nesta etapa, ao término das entrevistas, os sujeitos da pesquisa foram solicitadas a atribuir, por meio de uma escala de avaliação verbal, uma nota 1, 2, 3, 4 ou 5 ao grau de presença de cada característica na empresa pesquisada.

Considerando a natureza do presente estudo, a escolha para o tratamento dos dados direcionou-se para uma abordagem qualitativa, privilegiando procedimentos não-estatísticos, com análises mais estruturadas e subjetivas. O tratamento e a análise das evidências foram realizados com base na análise de conteúdo categorial, que consiste em levantar inferências a partir da identificação, nas falas dos entrevistados, de temas previamente extraídos do referencial teórico que apoia a pesquisa (ROESCH, 1999).

\section{APRESENTAÇÃO E ANÁLISE DOS RESULTADOS}

\subsection{EMPRESA PESQUISADA}

A empresa BITWAY está instalada, desde 1997, no Polo de Informática e Eletroeletrônica de Ilhéus. O incentivo fiscal, através da isenção de impostos sobre produtos industrializados, foi um dos principais motivos para definição do local da fábrica. A empresa atualmente produz e distribui seus computadores por todo o País, com produção mensal de 30.000 máquinas. Suas instalações ocupam uma área de 4.800 metros quadrados e cerca de 500 empregos diretos e indiretos são gerados por suas atividades. Os investimentos anuais da BITWAY em pesquisa e desenvolvimento (P \& D) se situam na faixa entre R \$ 1 milhão e R \$ 3 milhões.

A Figura 1 apresenta a estrutura simplificada da empresa e as conexões com seus parceiros. À direita podem ser vistas algumas das organizações com os quais a empresa pesquisada mantém alianças estratégicas: a ATA SERVIÇOS, a LÓGICO, a INCOEL e o Centro de Pesquisa de Ilhéus - CEPEDI, todas com sedes localizadas no polo de Ilhéus. Em março de 1998 o Grupo BITWAY se associou à MMC GROUP Inc., empresa localizada em Miami, Flórida, EUA, com o objetivo de facilitar o acesso a novas tecnologias, novos mercados e também a canais de distribuição.

Revista Ibero-Americana de Estratégia - RIAE, São Paulo, v. 11, n. 3, p. 05-32, set./dez. 2012. 
José Geraldo Pereira Barbosa, Nelson Lopes Marques Filho, Jorge Augusto de Sá Brito e Freitas \& Silvestre Prado de Souza Neto

Figura 1 - Estrutura simplificada da empresa pesquisada e relação com parceiros.



Fonte: Elaborado pelos autores.

\subsection{AÇÕES ESTRATÉGICAS IMPLANTADAS}

Ações e respostas estratégicas são identificadas pelo comprometimento significativo de recursos específicos ou distintos da organização. São difíceis de implantar e de reverter. Por sua vez, as ações e respostas táticas envolvem um menor número de recursos, sendo mais fáceis de implantar e reverter (HITT, IRELAND e HOSKINSON, 2003). A pesquisa identificou as seguintes ações estratégicas recentemente implantadas:

\subsubsection{IMPLANTAÇÃO DE UMA UNIDADE FABRIL EM PIRAQUARA - PARANÁ}

A condução de uma análise ambiental identificou dificuldades comerciais e logísticas para atingir o mercado da Região Sul do país. Como a empresa pretendia ter como mercado todo o território nacional, isso demandou, por questões de custos, que a produção de computadores estivesse mais próxima dos clientes daquela região. Por isso, em janeiro de 2008 , foi inaugurada a unidade fabril de Piraquara- PR, com uma área construída de $1.000 \mathrm{~m}^{2}$, gerando, de início, em torno de 60 (sessenta) empregos diretos e capacidade de produção para 5.000 máquinas/mês.

Ao implantar esse novo parque fabril longe da matriz, a empresa procurou agilidade em logística, facilidade na distribuição e flexibilidade dos negócios. Através dessa expansão, a empresa também visava iniciar exportações para o mercado latino-americano, com maior foco no MERCOSUL.

Revista Ibero-Americana de Estratégia - RIAE, São Paulo, v. 11, n. 3, p. 05-32, set./dez. 2012. 


\subsubsection{ADOÇÃO DE DESIGN MODERNO PARA MICROCOMPUTADORES E FABRICAÇÃO DE COMPUTADORES COM MARCAS DE TERCEIROS}

O propósito dessa ação foi o de criar diferenças, na percepção do cliente, entre a empresa e seus competidores. Para isso a empresa decidiu: (i) procurar nichos de mercado diferenciados, como por exemplo, netbooks coloridos (para atender o mercado adolescente e o feminino, por exemplo); e (ii) fabricar computadores (desktops e laptops) com marca de terceiros (parceiros e clientes), abdicando da exposição da marca própria, porém atendendo com exclusividade grandes clientes (magazines e redes de eletrodomésticos e eletroeletrônicos).

A empresa planeja implantar bases de dados para armazenamento de informações técnicas sobre produtos, apresentações do pessoal de vendas, táticas de vendas e relatórios de marketing, que possam ser compartilhados por todos e que possam originar ideias para melhorias em design.

\subsubsection{PARCERIA COM A EMPRESA LÓGICO PARA FABRICAÇÃO DE PLACAS DE MEMÓRIA}

A escolha dessa ação estratégica resultou da análise dos custos e benefícios de duas alternativas: focar em atividades de montagem de placas ou investir em desenvolvimento próprio de placas de memória, que exigiria contratar recursos humanos e realizar programas de treinamento. Frente a outros custos e dispêndios associados, ela preferiu realizar a atividade externamente, através de parceria com a empresa LÓGICO. Em nenhum momento a empresa analisou a opção por fusões ou aquisições.

Essa ação estratégica, nas palavras dos entrevistados, melhorou a qualidade do produto, acelerou o desenvolvimento e reduziu custos através de economias de escala decorrentes da exclusividade do parceiro no fornecimento de placas. Ficou evidente a opção preferencial da empresa por aquisição de conhecimento de fonte externa; entretanto, isso pode, em certa medida, comprometer sua capacidade própria de inovação no futuro.

\subsubsection{PARCERIA COM EMPRESA ATA PARA COMERCIALIZAÇÃO E VENDAS}

A empresa inicialmente comercializava seus produtos na região da Bahia. Para se expandir geograficamente, ela contratou os serviços da empresa ATA, que tem representantes em Belo Horizonte (MG), Salvador e Vitória (ES). Essa ação, apesar de não configurar um 
José Geraldo Pereira Barbosa, Nelson Lopes Marques Filho, Jorge Augusto de Sá Brito e Freitas \& Silvestre Prado de Souza Neto

comprometimento expressivo de recursos financeiros próprios, significou assumir uma posição de grande confiança na parceira.

Os entrevistados da BITWAY consideram que a ATA lhes auxilia bastante na análise do mercado, principalmente na análise de sensibilidade das variações de comportamento dos consumidores. Assim, essa parceria visa não só ao crescimento das vendas por todo o território nacional, mas também trazer para dentro da empresa as novas tendências, as necessidades dos clientes e a busca de novas oportunidades.

O fato de a empresa abrir mão de investir em pessoal próprio para análise do ambiente externo e em estrutura própria de vendas significa, mais uma vez, uma preferência da empresa pela aquisição de conhecimento de fonte externa e pode, no futuro, causar extrema dependência de parceiros. Tal ação é similar à anterior, no sentido de que a empresa opta por terceirização de atividades. A parceria inclui ainda a gestão - pela ATA - da rede de assistência técnica de pósvendas, que realiza todo o atendimento ao cliente. Através da ATA, a BITWAY recebe feedback dos problemas que eventualmente os computadores ofereçam, para correções de processos, procedimentos, rotinas e até de alterações de peças e componentes.

\subsubsection{IMPLANTAÇÃO DE UM SISTEMA ERP (ENTERPRISE RESOURCE PROGRAM)}

A empresa tem demonstrado dar muita importância à questão de avaliação de desempenho e, por isso, a Diretoria de Negócios foi incumbida da tarefa de empreender uma busca por um sistema de controle gerencial. Como primeiro passo, foi percebida a necessidade de um suporte de dataware, próprio de grandes empresas, ou seja, um ERP para gerenciar toda a empresa e obter dados para uma mensuração mais rápida. Esse sistema abrangerá inicialmente as áreas financeira, administrativa, de marketing e logística.

Tal sistema, além de representar investimento financeiro substancial, exigiu da empresa revisões em procedimentos, rotinas e processos para se adequar ao sistema. A implantação de tal sistema foi motivada pela vontade de melhorar o controle de processos e de rotinas até então não formalizadas.

A implantação do ERP levará a empresa a adquirir ou desenvolver outros softwares periféricos de controle gerencial e follow-up, como, por exemplo, o BSC - Balanced Scorecard. 


\subsubsection{ESTABELECIMENTO DE UMA REDE DE ASSISTÊNCIA TÉCNICA (PÓS-VENDAS)}

A fidelização do cliente no mercado de TI passa pela garantia usual e pela garantia estendida, ou seja, pela assistência técnica, traduzida por um gerenciamento de pós-vendas eficiente e próximo do cliente. Tal assistência técnica é vista como parte de uma estratégia de diferenciação de produtos e serviços de apoio ao cliente.

Esta ação estratégica compromete recursos não só financeiros, mas também a credibilidade da empresa, pelo fato de estabelecer parcerias com outras empresas para efetivar essa ação de pósvendas. Há-de se padronizar o atendimento com processos e procedimentos bem claros, para que todos os parceiros estejam em sintonia; de igual modo, é preciso reforçar relacionamentos jurídicos, visando contratos 'bem amarrados' entre BITWAY, ATA e terceirizados (rede de assistência técnica). Internamente, e junto aos parceiros contratados, é necessário se efetivar alteração de processos, visando a agilizar a expedição de peças de reposição (logística).

\subsubsection{IMPLANTAÇÃO DO PROJETO VAREJO DO BRASIL DE VENDAS PELA INTERNET}

O projeto Varejo do Brasil tem como objetivo a venda online de computadores diretamente da fábrica ao consumidor final. Visa à facilitação de pagamento, através de parcelas menores, a segmentos socioeconômicos de renda mais baixa.

A ideia da BITWAY é que cada usuário possa ter o computador que "sempre quis do jeito que você sempre sonhou”, como diz o slogan. A empresa acredita que cada brasileiro possa comprar online o seu computador, com as seguintes vantagens: faturamento direto da fábrica; financiamento através de instituições financeiras; garantia de fábrica válida por 1 (um) ano; rede de assistência técnica com cobertura nacional (feita pela ATA e terceirizados); e atendimento personalizado.

\subsection{ANÁlise DO PROCESSO DE ESCOLHA DAS AÇÕeS ESTRATÉGICAS: AVALIANDO A INFLUÊNCIA DAS CARACTERÍSTICAS}

Nesta seção, procurou-se avaliar a intensidade da presença, na empresa pesquisada, das características que são comuns a empresas que abordam a formulação de estratégia como um processo de aprendizagem. Esta avaliação foi realizada a partir, basicamente, da análise do processo de escolha das ações estratégicas descritas na seção anterior.

Revista Ibero-Americana de Estratégia - RIAE, São Paulo, v. 11, n. 3, p. 05-32, set./dez. 2012. 


\subsubsection{LIBERDADE PARA INTRAEMPREENDEDORISMO}

Do que se depreendeu de entrevistas e de observação direta, as iniciativas estratégicas em nível operacional são favorecidas e incentivadas pela facilidade de diálogo entre todos os níveis hierárquicos. A empresa apresenta uma estrutura bem simples, com poucos níveis hierárquicos entre a direção e a linha de produção. As instalações da empresa foram construídas num mesmo plano horizontal, separadas por divisórias que permitem que todos se comuniquem.

A empresa estimula seus colaboradores a se comunicarem direta e informalmente com todos os gerentes, incluindo os próprios sócios-proprietários. Citando os próprios sócios: “as portas aqui estão sempre abertas para que qualquer um possa vir oferecer sugestões de melhoria operacional, administrativa e eventualmente estratégica”.

A existência de espaços para o diálogo fica também evidenciada pela facilidade que se teve no acesso à empresa. As portas foram abertas para conversar e entrevistar qualquer pessoa. Houve oportunidade de almoçar no refeitório, um lugar público onde todos poderiam ouvir as conversas. Nessa ocasião e nesse local, os dois sócios conversaram abertamente sobre todas as ações estratégicas da empresa.

Na opinião de todos os entrevistados, deve haver clima organizacional que favoreça a gestão participativa, a qual jamais seria produtiva num ambiente de medos, reais ou imaginários. Eles informaram que tal gestão não ocorreria num ambiente onde o "chefe" (presidente, diretor, gerente, supervisor ou líder de qualquer processo) exerça seu "comando" na base do "eu mando, vocês obedecem" ou, o que é pior, "já tentamos isso uma vez e não deu certo". Em especial, os sócios e os parceiros da ATA SERVIÇOS relataram que, em empresas intensivas em conhecimento, não há espaço para esse tipo de atitude.

Segundo a Gerente de Certificação afirmou, o intraempreendedorismo também é estimulado na empresa por diversos programas, como seminários internos; reuniões periódicas de acompanhamento dos processos e procedimentos; e análise dos dados obtidos nas mensurações (correção de erros).

O Gerente de Produção afirmou que muitas das alterações ocorridas na linha de produção foram oriundas de ideias vindas do chão de fábrica. Segundo ele, à medida que os colaboradores aprendem sobre um processo, eles são estimulados a aperfeiçoá-lo (alterações em mudança física, processo e mensuração) por meio de comunicação e aval da seção de Certificação. Essa seção é a responsável por registrar a adoção do novo processo e das novas mensurações, e alterar o perfil das atividades correlacionadas. Para citar um exemplo, a alocação exclusiva de trabalhadores do sexo 
feminino nas atividades de triagem da linha de produção foi fruto de sugestões dos próprios constituintes da linha.

\subsubsection{PEQUENA ENNFASE EM PLANEJAMENTO E CONTROLE}

$\mathrm{Na}$ área de produção, as atividades de planejamento e controle são vistas como um fator determinante para a garantia de rígidos padrões de eficiência produtiva e obtenção de baixo grau de defeitos em produtos. As exigências para certificação ISO, por si só, deságuam em um sistema de planejamento e controle bem rígido. O controle, para o Gerente de Produção e para o sócio diretamente ligado à produção, é, portanto, uma atividade gerencial permanente. Por outro lado, no que se refere às atividades relacionadas ao desenvolvimento de novos produtos ou inovações, dentro da própria área de produção, os entrevistados entendem que uma ênfase excessiva em planejamento e controle não seria condizente com o ambiente dinâmico que cerca a empresa.

Diferentemente da área de produção, a área de negócios, por possuir uma estrutura mais flexível e ser responsável por atividades como vendas, marketing e desenvolvimento de novos produtos e mercados, coloca pouca ênfase em planejamento e controle. Destaque-se, entretanto, que uma das ações estratégicas selecionadas foi a implantação de um sistema ERP, já iniciado em 2009, e que pode mudar a atitude dessa área em relação ao planejamento e controle. Assim, a implantação do sistema ERP para gerenciar toda a empresa e obter maior facilidade de mensuração parece estar alinhada, contrariamente ao que se esperaria, com um desejo de obtenção de maior planejamento e controle.

De fato, a área de negócios se sente mais à vontade com os resultados alcançados (vendas, por exemplo) e não em planejar e controlar de forma intensa as ações necessárias para alcançar os resultados (não importa o caminho: através da ATA; pessoalmente; com as grandes redes varejistas de eletrodomésticos; ou diretamente ao consumidor, pela internet, através da criação da estrutura VAREJO DO BRASIL). Vale lembrar que, à época das entrevistas, a estrutura organizacional da empresa se mostrava muito simples e que na área de negócios se concentravam as atividades de marketing, financeiras, administrativas, de vendas e de logística.

Reforçando a necessidade de maior ênfase em atividades de planejamento e controle, os entrevistados relataram que o funcionamento adequado do setor de vendas e das outras áreas administrativas e financeiras não seria suficiente para colocar a empresa em condição de concorrer em um mercado onde se encontram nomes de grande tradição como Sony, HP, Dell, Toshiba, entre outras. Na análise de benchmarking, com os concorrentes, eles vislumbraram que a presença de 
José Geraldo Pereira Barbosa, Nelson Lopes Marques Filho, Jorge Augusto de Sá Brito e Freitas \& Silvestre Prado de Souza Neto

controles gerenciais poderia favorecer uma visão mais sistêmica da empresa e, consequentemente, melhor capacidade de avaliação de sua competitividade.

\subsubsection{FORÇA DA GERÊNCIA MÉDIA}

A empresa pesquisada é relativamente jovem (quatorze anos, aproximadamente) e com poucos níveis hierárquicos na sua estrutura. Entre os sócios proprietários e o chão de fábrica são encontrados apenas dois níveis hierárquicos: os gerentes gerais (o industrial e o de negócios) e os gerentes de seção. Em especial as ações: (i) criação de parque fabril fora da Bahia, (ii) montagem das placas de memória fora da empresa, (iii) alianças com parceiras na área de vendas e pós-vendas, e (iv) microcomputadores customizados com a marca do cliente ao invés da marca BITWAY foram todas intensamente apoiadas pelos gerentes.

A decisão pela parceria com empresa de vendas (ação iii) - a ATA - foi influenciada pela ênfase que os gerentes intermediários colocavam em expansão geográfica, penetração de mercado e atendimento integral ao cliente (com pós-vendas).

A ação (iv) adveio da sugestão dos sócios da ATA de que, para aumentar a presença da BITWAY em gôndolas de grandes varejistas de eletrodomésticos no Brasil, se usasse nos computadores a marca da própria rede e não a da BITWAY.

\subsubsection{GRANDE ÊNFASE EM APRENDIZAGEM DE LAÇO DUPLO}

Foi verificado, nas conversas e entrevistas, que as correções do rumo verificadas na empresa são baseadas em intuição e experiência dos gerentes e sócios da BITWAY e dos sócios da ATA, principalmente nas tomadas de decisão mais complexas, onde nem todas as variáveis são conhecidas.

De fato, algumas das ações estratégicas foram fruto de correções de rumo, como a implantação da unidade fabril no Paraná, que decorreu da dificuldade de comercialização na região sul do Brasil (a empresa pretendia anteriormente cobrir o território nacional a partir somente da Bahia); ou a implantação do atendimento pós-vendas (assistência técnica) através de terceirização (a empresa anteriormente pretendia executar com pessoal próprio).

Revista Ibero-Americana de Estratégia - RIAE, São Paulo, v. 11, n. 3, p. 05-32, set./dez. 2012. 


\subsubsection{PREFERÊNCIA POR ESTRUTURA ORGANIZACIONAL FLEXÍVEL}

Quando se analisa a estrutura da empresa pesquisada, verifica-se que ela tem efetivado várias alterações estruturais, desde a sua fundação, para se adaptar às mudanças de ambiente externo e interno.

A empresa apresenta alto grau de especialização horizontal, por tratar-se de empresa montadora de computadores, onde erros precisam ser evitados. Entretanto, essa alta especialização não se manifesta no sentido vertical (ou seja, as pessoas têm razoável grau de controle sobre o que fazem).

Quanto à formalização do comportamento, não há uma estrutura burocrática, com descrição de cargos, regras e regulamentos. Verificam-se na área de produção, no entanto, instruções específicas de montagem dos computadores.

Em termos de supervisão de tarefas, constata-se que ela já passou pelas etapas de supervisão direta e padronização dos processos de trabalho e hoje enfatiza a padronização dos resultados e das habilidades.

As ações estratégicas decorrentes dessa flexibilidade estrutural podem ser: (a) as alianças e parcerias com terceiros; e (b) a criação de um sistema de vendas pela internet. Essas escolhas demonstram que a empresa não pretende, pelo menos por enquanto, horizontalizar ou verticalizar atividades, mostrando interesse em permanecer com uma estrutura simples.

Na empresa ouve-se sempre que ser pequena e ágil é muito importante para que ela possa competir com as grandes empresas, como em frases do tipo:

“[...] a nossa empresa é extremamente competitiva; por isso, tentamos que o conhecimento seja gerado em um fluxo contínuo e dinâmico, porque sabemos que o ciclo de vida do produto é cada vez mais curto. Devemos, sobretudo, buscar avanço crescente da tecnologia da informação, mesmo que para tal precisemos abrir a empresa e atrair parcerias. A estrutura interna precisa estar sempre flexível às mudanças”

A leitura do ambiente, principalmente externo, é conduzida principalmente por meio de conversas entre os sócios e gerentes da BITWAY e da ATA, e centradas no que os concorrentes estão desenvolvendo ou tentando desenvolver. Uma estrutura mais rígida, com a formalização de reuniões e encontros, é sentida como podendo bloquear a livre expressão de ideias. 
José Geraldo Pereira Barbosa, Nelson Lopes Marques Filho, Jorge Augusto de Sá Brito e Freitas \& Silvestre Prado de Souza Neto

\subsubsection{GRANDE ÊNFASE EM ESTRATÉGIA DO TIPO 'GUARDA-CHUVA'}

A estratégia do tipo 'guarda-chuva', uma das características da escola estratégica da aprendizagem, foi identificada na empresa apenas no início de suas operações. Foi quando os sócios permitiram internamente que surgissem ideias sobre a estruturação da empresa e formas de trabalhar (principalmente na área de produção). Nessa época ainda eram incipientes as áreas funcionais de marketing, finanças e administrativa. A capacidade produtiva e os tipos de equipamentos fabris eram definidos pelas bases operacionais após receberem dos sócios as diretrizes abrangentes, deixando livres os níveis hierárquicos mais baixos para optar pelos tipos de produtos que seriam ou poderiam ser fabricados. As metas eram amplamente definidas pela liderança, permitindo aos outros atores, a decisão sobre como melhor alcançá-las. Assim, o objetivo maior era deliberado, mas o caminho em direção a esse objetivo emergia da gerência intermediária ou do chão de fábrica.

A empresa tinha uma linha mestra de fabricação e comercialização, porém os detalhes emergiam ao longo do próprio processo de implantação da fábrica. No caso das certificações, a equipe de certificação tinha grande liberdade de ação para consecução de seus objetivos.

\subsubsection{GRANDE ÊNFASE EM ESTRATÉGIA COMO PERSPECTIVA}

Não foram encontradas evidências fortes de que a empresa tenha olhado mais para seus recursos internos, capacidades e competências do que para o mercado quando decidindo por ações estratégicas. Essas parecem ter sido determinadas de forma relevante por análises de mercado, ou seja, uma preferência por estratégia como posicionamento parece mais condizente com o pensamento dos gestores da empresa.

\subsubsection{EMERGÊNCIA DE ESTRATÉGIAS NÃO PLANEJADAS}

Quanto às ações estratégicas, não foram encontradas fortes evidências de que algumas ações não tenham sido expressamente planejadas pela empresa. Entretanto, em decorrência do clima de abertura reinante na empresa e pela facilidade de acesso de todos os colaboradores à alta gerência, não se pode descartar a possibilidade de que uma 'ideia' tenha chegado aos ouvidos dos sócios, os quais, por sua vez, decidiram por implantar ações estratégicas específicas que seguissem tal 'ideia'. As parcerias com as empresas ATA e Lógico parecem ter surgido em função de dificuldades e 
problemas encaminhados por setores que não estavam envolvidos diretamente com planejamento estratégico.

\subsubsection{ORGANIZAÇÃO IMERSA EM AMBIENTE INSTÁVEL}

As organizações inseridas no setor de TI atuam em ambientes competitivos, caracterizados pela alta rivalidade entre os participantes e por clientes exigentes, que buscam soluções customizadas que possam atender suas necessidades e desejos específicos. Logo, estão imersas em um ambiente de difícil previsão.

O ambiente é muito favorável aos clientes em função da existência de uma oferta generosamente diversificada e cada vez mais crescente de produtos e serviços de TI. Essa quantidade de opções torna extremamente difícil o desenvolvimento de um programa bem sucedido que garanta a fidelidade de clientes, restando aos fornecedores de TI lidar com a consequente alteração da sua base de clientes e a possível erosão das vantagens competitivas.

Um dos sócios afirma:

"[...] é preciso mudar constantemente porque o ambiente em que estamos situados, com inovações constantes e preços mais baixos, não nos permite ficar estabilizados, se considerando pronto, [...] precisamos de desenvolvimento constante em todas as áreas para nos antecipar às exigências do mercado crescente."

Foi verificado durante as entrevistas que "para competir em ambientes complexos e dinâmicos, a empresa BITWAY precisa trabalhar no limite de desempenho de produção de modelos existentes e de modelos novos".

\section{CONSIDERAÇÕES FINAIS}

A leitura do referencial teórico deste trabalho indicou que algumas características são comuns às empresas onde o processo de formulação de estratégias empresariais é entendido de forma relevante como um processo de aprendizagem. Essas características são: liberdade para intraempreendedorismo; pequena ênfase em planejamento e controle; força da gerência média; grande ênfase em aprendizagem de laço duplo; preferência por estrutura organizacional flexível; grande ênfase em estratégia como perspectiva; grande ênfase em estratégia como guarda-chuva; emergência de estratégias não planejadas; e organização imersa em ambiente instável. 
José Geraldo Pereira Barbosa, Nelson Lopes Marques Filho, Jorge Augusto de Sá Brito e Freitas \& Silvestre Prado de Souza Neto

Para avaliação da presença dessas características na empresa pesquisada, foram realizadas entrevistas com os sujeitos da pesquisa para identificação de ações estratégicas implantadas na empresa e o processo de escolha das mesmas. Assim, sete ações estratégicas foram identificadas: implantação de uma unidade fabril no Estado do Paraná; adoção de design moderno para microcomputadores e fabricação de computadores com marcas de terceiros; parceria com a empresa LÓGICO para a fabricação de placas de memória; parceria com a empresa ATA para comercialização e vendas; implantação de um sistema ERP para gerenciar toda a empresa e obter mensuração mais rápida; estabelecimento de uma rede de assistência técnica (pós-vendas); e implantação do projeto rede de vendas pela internet - Programa Varejo do Brasil.

Com relação à presença das características acima elencadas, foi possível constatar que quatro características - intraempreendedorismo, força da gerência intermediária, estrutura flexível e ambiente externo instável - estão bastante presentes na empresa; duas características - pequena ênfase em planejamento e controle; e emergência de estratégias não planejadas - podem ser enquadradas como grau médio de presença; e três características - ênfase em estratégia como guarda-chuva; ênfase em aprendizagem de laço duplo; e ênfase em estratégia como perspectiva - se mostraram pouco presentes.

Portanto, os resultados sugerem que o processo de formulação de estratégia da empresa pesquisada é entendido, basicamente, como um processo de aprendizagem. A pesquisa permitiu constatar que na BITWAY, uma empresa brasileira de porte médio, fabricante de computadores e localizada longe dos principais centros urbanos do País, as ações estratégicas mais eficazes não se desenvolveram mediante processos claros, bem ordenados, controlados e explícitos, mas foram moldadas, de forma relevante, por um processo de aprendizagem centrado na trajetória passada da empresa. Em outras palavras, reflexões sobre os efeitos de ações originalmente planejadas promoveram ajustes substanciais nas mesmas, tornando-as, em certa medida, emergentes. Os sócios reconhecem que, mais do que conceber estratégias, eles de fato gerenciam o processo de sua criação e implantação.

Ressalve-se que a maior limitação desse estudo se prende ao fato de se explorar um caso único, isolado, que a par de possibilitar extrapolações teóricas, não permite, entretanto generalizações estatísticas.

Revista Ibero-Americana de Estratégia - RIAE, São Paulo, v. 11, n. 3, p. 05-32, set./dez. 2012. 
Estratégia como Processo de Aprendizagem: Um Estudo Empírico de seus Fatores Determinantes em uma Empresa de TI

\section{REFERÊNCIAS}

Ackoff, R. L. (1979) Planejamento empresarial. Rio de Janeiro: Livros Técnicos e Científicos.

Andrews, K. R. (2006) O conceito da estratégia corporativa. In: MINTZBERG, H. et al. O processo da estratégia: conceitos, contextos e casos selecionados. Porto Alegre: Bookman, 2003, reimpr.

Ansoff, H. I. (1987) Do planejamento estratégico à administração estratégica. São Paulo: Atlas.

(1991) A nova estratégia empresarial. São Paulo: Atlas.

(1993) Implantando a administração estratégica. São Paulo: Atlas.

Argyris, C. (1977) Double loop learning in organizations. Harvard Business Review, v. 55, n. 5, p. 115-126.

Blackler, F. (1995) Knowledge, knowledge work and organizations: an overview and interpretation. Organization Studies, v. 16, n. 6, p. 1021-1046.

Burgelman, R. A. (1983) Corporate entrepreneurship and strategic management: insights from a process study. Management Science, v. 29, n. 12, December.

Collier, N.; Fishwick, F.; Floyd, S. W. (2004) Managerial involvement and perceptions of strategy process. Long Range Planning, v. 37, p. 67-83.

Crossan, M.; Lane, H. W.; White, R. E. (1999) An organizational learning framework: from intuition to institution. Academy of Management Review, v. 24, n. 3, p. 522-537.

Dierickx, I.; Cool, K. (1989) Asset stock accumulation and sustainability of competitive advantage. Management Science, v. 35, n. 12, p. 1504-1513.

Gil. A. C. (1994) Como elaborar projetos de pesquisa. São Paulo: Atlas.

Hill, C. W. L. (1994) International business: competing in the global marketplace. Homewood, IL: Richard Irwin.

Hill, C. W. L.; Jones, G. R. (2004) Strategic management theory: an integrated approach. 6. ed. Boston, MA: Houghton Mifflin.

Revista Ibero-Americana de Estratégia - RIAE, São Paulo, v. 11, n. 3, p. 05-32, set./dez. 2012. 
José Geraldo Pereira Barbosa, Nelson Lopes Marques Filho, Jorge Augusto de Sá Brito e Freitas \& Silvestre Prado de Souza Neto

Hitt, M. A.; Ireland, R. D.; Hoskisson, R. E. (2003) Administração estratégica. São Paulo: Thomson.

Levitt, B.; March, J. G. (1988) Organizational learning. American Review of Sociology, v. 14, p. 319-340.

Liao, S.H; Fei, W.C; Liu, C.T. (2008) Relationships between knowledge inertia, organizational learning and organizational innovation. Technovation, v. 28, 4, p. 183-195.

Meyer, A. D.; Goes, J. B. (1988) Organizational assimilations of innovations: a multilevel contextual analysis. Academy of Management Journal, v. 31, n. 4, p. 897-923.

Mintzberg, H. (1978) Patterns in strategy formation. Management Science, v. 24, n. 9, p. 934-948.

(1987) Crafting strategy. Harvard Business Review, v. 65, n. 4, p. 66-75.

(1994) The fall and rise of strategic planning. Harvard Business Review, v. 72, n. 1, p. $107-114$.

Mintzberg, H., Ahlstrand, B., Lampel, J. (2006) O processo de estratégia: conceitos, contextos e casos selecionados. Porto Alegre: Bookman.

Mintzberg, H.; Ahlstrand, B.; Lampel, J. (2000) Safári de estratégia: roteiro pela selva do planejamento estratégico. Porto Alegre: Bookman.

Nonaka, I. (1994) A dynamic theory of organizational knowledge creation. Organization Science, v. 5, p. 14-37.

Nonaka, I.; Takeuchi, H. (1997) Criação de conhecimento na empresa. Rio de Janeiro: Campus.

Pettigrew, A. M. (1977) Strategy formulation as a political process. International Studies of Management \& Organization, v. 7, n. 2, p. 78-88.

Polanyi, M. (1962) Personal knowledge: toward a post critical philosophy. New York: Harper Torchbooks.

Quinn, J. B. (1989) Strategic change: logical incrementalism. Sloan Management Review, v. 30, n. 4, p. 16-41.

Roesch, M. A. S. (1996) Projetos de estágio do curso de administração: guia para pesquisas, projetos, estágios e trabalhos de conclusão de curso. São Paulo: Atlas.

Revista Ibero-Americana de Estratégia - RIAE, São Paulo, v. 11, n. 3, p. 05-32, set./dez. 2012. 
Estratégia como Processo de Aprendizagem: Um Estudo Empírico de seus Fatores Determinantes em uma Empresa de TI

Taylor, J; MCadam, R. (2004) Innovation adoption and implementation in organizations: a review and critique. Journal of General Management, vol.30. Fall.

Vergara, S. C. (2005) Projetos e relatórios de pesquisa em administração. 6. ed. São Paulo: Atlas.

Walsh, J. P. (1995) Managerial and organizational cognition: notes from a trip down memory lane. Organization Science, v. 6, n. 3, p. 280-321.

Walsh, J. P.; Ungson, G. R. (1991) Organizational memory. Academy of Management Review, v. 16 , n. 1, p. 57-91.

Weick, K. E. (1979) The social psychology of organizing. 2. ed. New York: McGraw-Hill.

Weick, K. E.; Roberts, K. H. (1993) Collective mind in organizations: heedful interrelating on flight decks. Administrative Science Quarterly, v. 38, p. 357-381.

Recebido: 03/08/2012

Aprovado: 08/10/2012

Revista Ibero-Americana de Estratégia - RIAE, São Paulo, v. 11, n. 3, p. 05-32, set./dez. 2012. 